Article

\title{
Introducing Risk Considerations into the Supply Chain Network Design
}

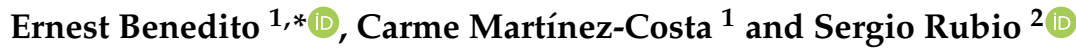 \\ 1 Department of Management, Universitat Politècnica de Catalunya, 08028 Barcelona, Spain; \\ mcarme.martinez@upc.edu \\ 2 School of Industrial Engineering, Universidad de Extremadura, 06006 Badajoz, Spain; srubio@unex.es \\ * Correspondence: ernest.benedito@upc.edu
}

Received: 29 May 2020; Accepted: 24 June 2020; Published: 26 June 2020

\begin{abstract}
Supply chains (SC) aim to provide products to the final customer at a certain service level. However, unforeseen events occur that impede supply chain objectives. SC Risk has been studied in the literature, providing frameworks and methodologies to manage SC failures. Nevertheless, more efforts are needed to prevent hazardous and disruptive risks and their consequences. These risks must be considered during the process of designing a supply chain. Some methodological contributions concerning risk in the supply chain network design (SCND) are conceptual frameworks for mitigating SC disruptions, which suggest strategies and measures for designing robust and resilient SCs. Although such contributions are valuable, they do not indicate how to cope with risk when designing a SC. The main objective of this research is to describe a methodology aimed at including risk considerations into the SCND. Our proposal aims to be, on the one hand, a comprehensive approach that includes a risk identification and assessment procedure in each of the stages of the SCND process and, on the other hand, a tool for decision-making in SC design or redesign processes when SC risks need to be considered. The methodology proposed is an extension of a SCND methodology including risk considerations in order to improve the performance of the supply chains. A case study illustrates how the proposed methodological works, achieving the identification of SC risks already observed in previous works.
\end{abstract}

Keywords: supply chain; supply chain network design; logistics; supply chain risk

\section{Introduction}

Globalisation, advancing technology, increasingly demanding customers, product complexity, and short product and technology lifecycles all result in more complex and vulnerable supply chains [1-6]. In addition, unforeseen events may occur beyond a firm's control and generate supply chain disruptions (see [7]). As such, adequate supply chain design is needed to become more resilient and less vulnerable to disruptions or unpredictable events.

Supply chain disruptions can be described as unplanned and unanticipated events that disrupt the normal flow of goods and materials within a supply chain (SC) and, as a consequence, expose firms to operational and financial risks $[3,8,9]$. Supply Chain Risk Management (SCRM) attempts to interpret and avoid the negative effects of any disruption in an SC [10]. SCRM is a well-known area of activity, both in academia and consulting. SCRM has largely focused on proposing measures to be applied at an operational level [11]. Nevertheless, recent research highlights the crucial role of risk consideration on supply chain network design (SCND) [12,13]. SC should be designed not only with the objective of optimising operational procedures, but also with the goal of achieving resilience [13].

The way in which a SC is designed has important implications not only for the performance of the SC [14-16] but also for dealing with potential SC risks [13]. Nevertheless, according to Corominas et al. [16], most of the contributions to the SC design literature are based on proposing 
mathematical programming models, which cannot include all the qualitative and quantitative decisions necessary to determine a SC configuration. So, a methodology to formalise the decisions that should be taken during the SC design process would facilitate the consideration of all the relevant aspects of a SC design, including the potential SC risks. Some methodological contributions concerning risk in the SCND are conceptual frameworks for mitigating SC disruptions, which suggest strategies and measures for designing robust and resilient SC $[17,18]$. Although all these contributions are valuable, to the best of our knowledge, there is not any comprehensive methodology to guide how to cope with risk in the whole process of designing the SC.

The main objective of this research is to describe such a methodology aimed at including risk considerations into the SCND. Our proposal aims to be, on the one hand, a comprehensive approach that includes the risk identification and assessment in each of the stages of the SCND process and, on the other hand, a tool for decision-making when SC risks need to be considered in SC design or redesign processes. In order to achieve this goal, the following research questions (RQ) are proposed:

- $\quad$ RQ1: What type of risks should be considered when designing an SCN?

- RQ2: What decisions can be made in the SCND to (attempt to) avoid the effects of SC disruptions?

The structure of the rest of this paper is as follows. Section 2 exhibits a summary of the SC risk classifications provided in the extant literature of SCND according to the risk source and its consequences. Section 3 presents a methodology, the so-called Supply Chain Outline Process with Risk (SCOP-R), designed to include risk considerations into the SCND, while Section 4 provides a case study to illustrate how to apply the SCOP-R methodology, which risks should be considered in each stage of the SC design process, and what design decisions should be made accordingly. Finally, Section 5 closes the paper with the conclusions and future lines of research.

\section{Supply Chain Risk: Definition and Classifications}

SCRM has been a hot topic in recent supply chain management research [19]; at least five systematic literature reviews have been conducted in recent years, providing some insight into the state-of-the-art assessment of SCRM ([20] and references therein). Some of the studies related to supply chain risk (SCR) have focused on categorising and distinguishing between types of risk, but there is still no consensus on which typology or framework best captures the different types of SCRs [5,10,21]. Similarly, definitions of SC risk are often vague, ambiguous, and defy quantification [22]. However, Heckmann et al. [22] (p. 121) provide a description of the evolution of the term risk, as well as a discussion about different approaches to the concept of SCR and its main characteristics; in doing so, they observe that, "although the topic is being considered as increasingly important, there are only a few authors explicitly defining supply chain risk." Nevertheless, some common elements are usually cited to express the concept of risk:

- Sources of risk: elements which have the potential to generate risk, such as natural disasters or man-made events.

- Drivers or triggering events: events whose occurrence can change a particular set of circumstances, e.g., earthquake and labour strikes.

- Consequences: the outcome of an event, e.g., damaged facilities and infrastructure or manufacturing stoppages.

- Probability of occurrence: chance of something happening.

Similarly, Díaz-Curbelo et al. [23] stress that risk events are caused by a set of factors or agents that can lead to different impacts. Several relationships among agents of risk (causes) can be defined, as well as for events of risk, which should be considered when implementing mitigation strategies.

For the proposal of this research, the following definition of SCR is considered: "Supply chain risk is the potential loss for a supply chain in terms of its target values of efficiency and effectiveness 
evoked by uncertain developments of supply chain characteristics whose changes were caused by the occurrence of triggering-events" [22] (p. 130).

Regarding SC risk classifications, two criteria are mainly utilised to classify SC risks. Although some authors focus on categorising the risk sources, others focus on categorising SCR based on their consequences (or their negative impact on SCs) and the probability of their occurrence. Some contributions in this regard will be reviewed in the following subsections.

\subsection{Risk Sources}

SCRs are driven by a variety of internal and external sources of vulnerability $[4,13]$. For example, Vlajic et al. [18] distinguish between internal and external sources of vulnerability, although they focus mainly on internal sources of vulnerability. Such internal sources are observed at supply chain level and at company level. Likewise, the authors identify generic sources of SC vulnerability as well as specific sources related to food SC. Similarly, Klibi et al. [14,24] distinguish among three broad categories of SC vulnerability sources: endogenous assets (equipment, human resources, inventories, distribution, recovery, and service centres), SC partners (customers, suppliers, and subcontractors), and exogenous geographical factors (natural disasters, major accidents, and wilful attacks).

Likewise, Viswanadham et al. [25] state that SCR can arise at four levels: organisational level, network level, industry level, and environmental level. Similarly, Rao et al. [2] develop a typology of risks sources in the SC, based on different types of uncertainties regarding environmental risks (political, macroeconomic, social, and natural), industry risks (inputs market, demand, and competition), organisational risks (operating, liability, credit, and agency uncertainties), problem-specific risks (internally managed by organisations), and decision-maker related risk variables (including knowledge, experience, biases, and bounded rationality of the decision-makers).

Based on the review and synthesis of the extant literature related to SC risk sources, Hudnurkar et al. [5] propose a risk classification framework according to several risk sources: product characteristics, supply chain management processes (information systems, source, make, deliver, and return processes), SC infrastructure (transportation and facilities), external environment, and human resources.

\subsection{Risk Consequences}

Nowadays, one of the most common ways of distinguishing SC disruptions events in the Operations Management literature is according to their consequences in terms of impact and frequency $[26,27]$. Based on these elements (impact and frequency), several classifications have been proposed in the literature.

Viswanadham et al. [25] provide a typology of SCR based on the severity in terms of its negative impact on business operations, distinguishing among deviation, disruption, and disaster. [14,24], on the other hand, propose characterising decision-making situations based on the quality of the information available. Three types of uncertainties may be distinguished: random (related to business-as-usual operations and low-impact events), hazard (low-probability, high-impact, and unusual events), and deep uncertainty (lack of any information to assess the likelihood of plausible future extreme events). Later, Klibi et al. [28] classify plausible future events relevant to SCN modelling in terms of information availability and impact.

Similarly, Heckmann et al. [22] classify unexpected events (triggering events) according to their probability of occurrence and related consequences. Several terms are used to refer to triggering events: disturbance (deviation from what is typical or expected), disruption (more severe and often persist for a longer period of time than a disturbance), disaster, hazard, or crisis. Likewise, [29] also categorise SCRs into two major classes: operational risks, arising from uncertainties in matching supply and demand, and disruption risks, caused by natural disasters as well as man-made disruptions. A similar approach is employed in [12] where recurrent and disruptive risks are distinguished. 
Focusing on low-probability and high-impact risks, Akkermans et al. [26,30] propose a typology of SC tsunamis defined as low-probability, high-impact events with a highly unforeseeable, immediate, and highly destructive impact or disruptive effects. The authors state that although it is difficult, SC tsunamis are predictable and even avoidable.

From all of the aforementioned studies, it is clear that there is no standard classification including the diverse criteria (sources, frequency, and impact), and there is even a lack of consensus on the terminology of SC risks $[5,10]$. However, a risk classification system would be useful to facilitate effective risk identification and thereby risk assessment [31]. Thus, in order to achieve the research goals, we propose to analyse and summarise the risk typologies according to the risk source and its consequences, as shown in Table 1. This typology will be used to identify risks in the SCND process, according to the methodology described in the following section.

Table 1. A supply chains (SC) risks typology.

\begin{tabular}{|c|c|c|c|}
\hline Category & Criteria & Risks & References \\
\hline \multirow[t]{2}{*}{ Risk Resources } & $\begin{array}{ll}- & \text { Internal } \\
- & \text { External } \\
\end{array}$ & $\begin{array}{l}\text { - Internal: endogenous assets, operational, product characteristics, } \\
\text { transportation, facilities, human resources } \\
\text { - External: SC partners, geographical factors, information, } \\
\text { financial issues, environment }\end{array}$ & {$[4,13,14,24]$} \\
\hline & $\begin{array}{l}\text { Entity level and } \\
\text { uncertainty: } \\
-\quad \text { Organisation } \\
-\quad \text { Industry } \\
-\quad \text { Network } \\
-\quad \text { Environment } \\
-\quad \text { Decision-maker }\end{array}$ & $\begin{array}{l}\text { - Organisation: labour uncertainty, raw material shortages, quality changes, } \\
\text { spare parts restrictions, machine failure, product liability uncertainty, } \\
\text { recalls, credit and agency uncertainty } \\
\text { Industry: quality input, market supply shifts, changes in consumer tastes, } \\
\text { availability of substitute goods, scarcity of complementary goods, } \\
\text { new entrants, rivalry, technological uncertainty } \\
\text { - Network: complexity, density, node criticality } \\
\text { - Environment: political instability, shifts in government policy, } \\
\text { and macroeconomic, social, and natural uncertainties } \\
\text { - Decision-maker: decision-maker's knowledge, skills, experiences, biases, } \\
\text { and institutional rules }\end{array}$ & {$[2,8,25]$} \\
\hline Risk Consequences & $\begin{array}{ll}- & \text { Deviations } \\
- & \text { Disruptions } \\
- & \text { Disasters }\end{array}$ & $\begin{array}{l}\text { Deviations: operational variations in demand, supply, procurement, } \\
\text { production and logistics costs, transportation, production, lead-times } \\
\text { Disruptions: nonavailability of certain production, warehousing, } \\
\text { and distribution facilities or transportation due to unexpected events } \\
\text { caused by human or natural factors } \\
\text { Disasters: a temporary irrecoverable shut-down of the SC due to } \\
\text { unforeseen catastrophic system-wide disruptions }\end{array}$ & {$[12,22,25,29]$} \\
\hline
\end{tabular}

\section{The SC Network Design Framework with Risk Consideration}

In this section, we propose a new methodology to consider risk in SCN design decisions. The methodology is based on the Supply Chain Outline Process (SCOP) framework [16]. SCOP is a hierarchical top-down method aiming to provide a framework for decision-making about the SC configuration. Its goal is formalising the decisions that should be taken during the design process (Figure 1). 


\section{Stage 1: Object, environment and objectives}
1. Definition of the SC object
2. Analysis of the environment (scenarios and potential markets)
3. Determination of the objectives.

\section{Stage 2: Definition of SC macrostructure}

1. Identification of activity blocks and relation between them

2. Analysis of recovery options

3. M-graph

\section{Stage 3 Definition of SC mesostructure}

1. According to the product structure and production process

2. Options for each SC activity or group of activities

3. Specification of a mode for each main vertex of every recipe

4. m-graph

\section{Stage 4: Definition of SC microstructure}
1. List of facilities where the recipes can be done
2. Sources of demand
3. Means of transport between facilities or facilities and sources of demand
4. $\mu$-graph
5. Mathematical model

\section{Stage 5: choose of $\mathrm{SC}$ configuration}
1. Selection of SC configuration
2. Definition of protocols in case of incidents
3. Implementation of the SC

Figure 1. General layout of Supply Chain Outline Process (SCOP) (Adapted from [16]).

Although SCOP authors acknowledge a strong propensity of the SC to be disturbed by natural and non-natural factors, and the relevance of the SC design process for dealing with risk situations along the SC, SCOP does not explicitly include risk considerations throughout the decision process.

Our proposal, called the SC Outline Process with Risk consideration (SCOP-R), aims to help SC network designers to make decisions considering the associated risks that could affect the SC's performance. The SCND decisions in SCOP-R are hierarchically organised in four stages. Each stage provides a description of the main decision to make and identify the main risks associated with each one. When using SCOP-R, the decision-maker must be aware of the impact of the risks before making each decision. Unfortunately, evaluating and quantifying the impact of risks in the early stages of the methodology is difficult, if not directly impossible, as usually, one needs a deeper knowledge of the SC design, acquired with the decision in later stages (e.g., risk of selection of suppliers, quality failures, etc.). Consequently, we propose a forward-and-backward procedure where in each stage, the decision-maker identifies and assesses the risks using the available information and, when it is appropriate, modifies the decisions made in the previous stages of the design of the SC (see Figure 2). The explicit incorporation of the risk factor in the SC design process allows, therefore, the decision-maker to reformulate decisions taken in previous stages of the SCOP, generating a feedback mechanism. 


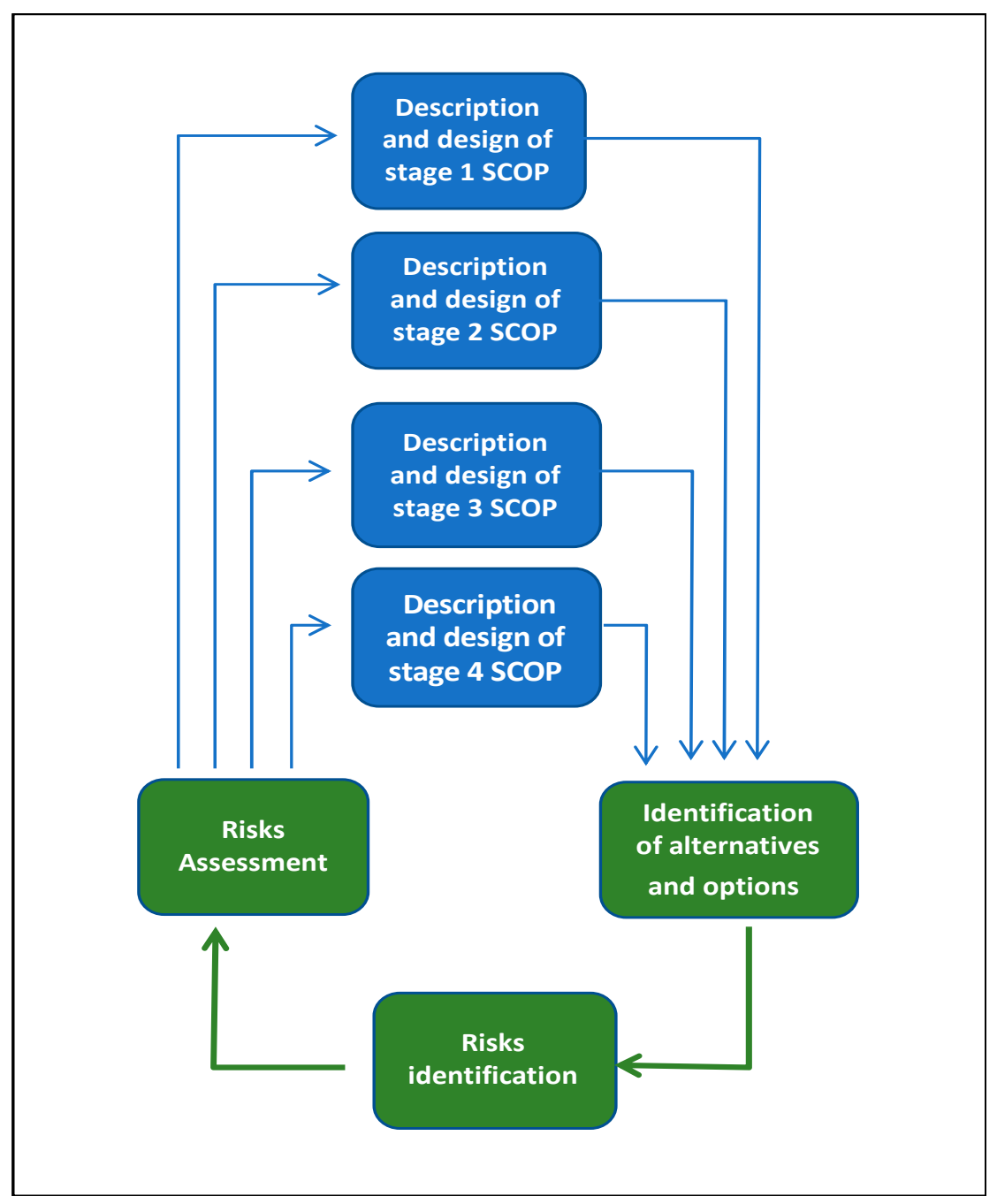

Figure 2. Procedure for the consideration of risk in the design of the Supply chains (SC).

The rest of this section describes each stage of SCOP-R as follows. First, it describes the corresponding SCOP stage and its main decisions. Next, SC design options and alternatives are provided, and the risks associated with these decisions are identified. Finally, an assessment is made of the previously identified risks that, depending on the level of risk assumed by the decision-maker, will lead to the acceptance or rejection of that risk, and, in this case, the need to formulate new design alternatives.

\subsection{Stage 1: Object, Environment, and Objectives}

In the first stage of the SCOP methodology, the basic elements of the SC are defined as its object, environment, and objectives. According to the defined object and environment, SC may be more or less vulnerable to different types of risks. Actually, risk impacts can vary according to the type of product (object) or market (environment) [13], so the decisions made at this stage must consider potential risks and their associated effects.

Regarding the purpose of the SC, this should include a definition of the product, as well as a characterisation of the potential markets, given that these decisions may have vital implications in the generation of threats in the SC [16]. In addition, the object must include any other product characteristic which can be used to define it in a proper and precise way. For example, its product life cycle, raw materials, and even market can be included in the definition of the SC's objective. Regarding the environment, Melnyk et al. [32] include several factors that constrain and influence the overall nature of the SC: business models, and political, economic, technological, industrial, and adjacent elements. 
According to [16], objectives are subordinated to the SC object and may include profit maximisation, cost or responsive time minimisation, quality, robustness, resilience, or a variety of these factors.

According to the object, the environment, and the objectives defined for each potential scenario, the risks related to each will be identified by exploring the risk sources identified in Table 1: regarding SC vulnerability criteria, analysing potential external risks; at the entity level and from uncertainty criteria, exploring potential risks related to the organisation, industry, network, and environment; finally, identifying potential product and environment risks from the dimension's criteria risk sources.

Different SC risk effects can be observed according to the SC objectives. In this sense, different competitive priorities, e.g., cost reduction or responsiveness, have different intrinsic vulnerabilities [13,33], so facing the risk implications associated with the defined SC goals is necessary. For example, a focus on cost reduction by applying lean practices, offshoring, or outsourcing operations can make an SC vulnerable [20,34]. Lean practices usually imply a low level of inventory, so when there is a disruption, the SC cannot match supply and demand. Similarly, offshoring and outsourcing practices imply that the SC is more geographically diverse, and therefore, exposed to all sorts of disruption [35].

Once the risks are identified, the risk consequences and their impact on the fulfilment of the objectives will be analysed. Finally, the possibility of modifying the object of the chain will be assessed.

For example, regarding the risks related to the product, Hudnurkar et al. [5] provide a set of risks associated with the product characteristics, such as nature and composition of raw materials, product obsolescence and perishability, inadequate packaging, or unacceptable quality, among others. The consequences of these risks can largely be defined as low impact, high frequency risks (LIHF). Similarity, several high impact, low frequency risks (HILF) may be considered to be related to the definition of the SC's environment, which can be generated by external causes: natural disasters, climate, plagues, political or social instability, regulations, piracy, terrorism, cultural characteristics, etc.

At this stage of the SC design, the risk impact assessment should be approximate since there is not enough information available to make a detailed assessment. In this case, that analysis will be carried-out at a later stage in the design of the SC in order to accurately assess whether it modifies the object or objectives of the SC.

As we have noted previously, the consideration of risk in the design of the SC involves an iterative procedure which converges when risk consequences are acceptable to the organisation (risk acceptance). However, this willingness to accept a risk does not mean that it can be ignored [20]. On the contrary, it should continue to be tracked to ensure that the accepted consequences do not escalate [20]. Naturally, if the consequences derived from the risk exceed a certain threshold, the elements included in this stage of the SC design must be redefined until a level of risk acceptable to the organisation is reached.

\subsection{Stage 2: Macrostructure}

The macrostructure of the SC is defined by the presence of the large blocks of activities that make up the basic scheme of the chain and their relationships. The block P includes those activities related with procurement, production, and distribution processes. The block $\mathrm{U}$ defines markets and customers of the SC. Reverse logistics activities such as collection (C), disposal (D), recovery (R), and secondary markets (S), can be also defined in the macrostructure. Some examples are described in Figure 3, and a discussion about the presence of these blocks is provided as follows.

Regarding P block, all SCs used to involve procurement, production, and distribution activities. Indeed, it is difficult to imagine an SC without this type of activities, so we can assume that this type of configuration (P block) will be present in every SC, as the default option. Every SC can be described by its market and a set of customers or users (U block). However, the characteristics of such a market may determine the assumption of several risks. It is likely that the main decision in this regard is whether the SC market will be global or local. Regarding reverse logistics activities (C, D, R, and S blocks), nowadays, most SCs on the whole include important activities related to the return flow of products from consumer to manufacturer; however, its presence in the SC may be a decision that needs to be made during this stage of the design process. Although the literature of closed-loop supply chains (CLSC) network design 
considering risk is still in its infancy [36], some consequences (risks) of closing an SC can be identified regarding the relations with suppliers, distributors, and customers [37]. Reverse logistics activities may impact design, sales, purchasing, production, distribution, after sales services, and accounting departments. In addition, reverse logistics functions may influence make-or-buy decisions related to parts or new products [37]. Similarly, Rubio et al. [38] describe strategic, tactical, and operational implications derived from the implementation of reverse logistics systems (RLS).
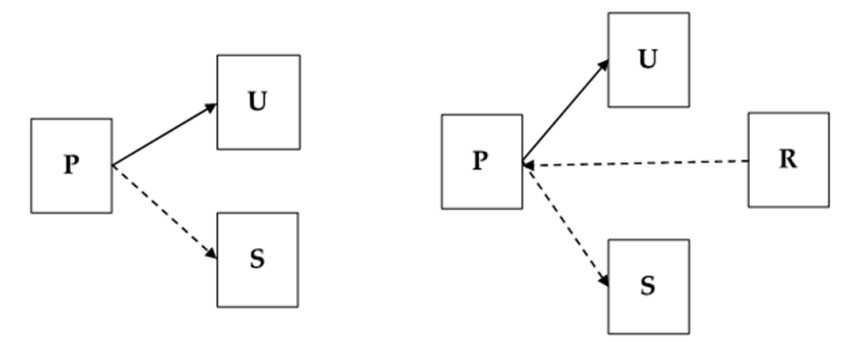

P block: Supply, Production and Distribution activities

U block: Users, market, consumers

S block: Secondary markets

R block: Remanufacturing/recycling activities

C block: Collection of End-of-Use products

D block: Disposal

Figure 3. Macrostructure for three potential scenarios.

\subsection{Stage 3: Mesostructure}

In this stage, the type or types of relationship that must exist between the blocks of activities of the macrostructure is decided. To do this, once the product structure and the production process of the SC are determined, the various options to carry out the activities will be analysed considering the risks associated with each option. The risks identified in the first and second stages of SCOP-R will be taken into account and new potential risks will be identified by exploring the risk sources revealed in Table 1 . From SC vulnerability criteria, the internal risks will be considered; from entity level and uncertainty criteria, the risks related to the organisation, industry, network, and decision-maker will be studied; and from dimensions criteria, the product, processes, infrastructure, and human resources related risks will be reviewed. Finally, the options most consistent with the decisions taken by the company in stage 1 will be chosen.

The most relevant risks associated with the main options for carrying out the activities are described below.

\subsubsection{Procurement and Production Activities}

Although SCOP considers five options related to procurement and production activities, to illustrate how to include risk decisions in this stage of the design process, they are grouped in three main options: make, buy from a single or several suppliers, and buy in spot markets.

- P1: Make. Some risks associated with the decision of manufacturing the product in-house are related to:

Operational disruptions due to natural or man-made events (HILF risks)

- Capacity issues

- Technological obsolescence

$\bigcirc \quad$ Design changes 
- P2: Suppliers relationships. Supply risk (supplier selection and assessment) should likely be considered as one of the most prolific topics of research in SCRM. For the purpose of this research, regardless of the type of such relationships (number of suppliers, long-term or short-term relationships, etc.), this procurement option can be linked to several risks:

- Supply disruptions: supplier failure, supplier reliability, supplier quality issues, etc.

Knowledge dissemination and intellectual property.

$\bigcirc \quad$ Outsourcing risks: supplier reliability, transportation risk, country risk, exchange rate risk, etc.

- P3: Spot markets. When the product acquisition is made in spot markets, several risks might occur:

Market shortages and availability of quality supply

Price volatility

The selection among the options depends largely on the degree of modularity of the product, the trade-off between criteria of reliability and cost, and the risk involved in each option.

As Chopra et al. [39] point out, the most significant decision regarding any function in the SC is "whether to outsource the function or perform it in-house". They state that this decision makes sense if the outsourcing process improves the performance of the SC, generating a surplus in the SC, without seriously affecting the risk: "outsourcing the function is preferable if the growth of surplus is large with a small increase in risk". Subsequently, in this phase of the SC's design, we will consider the possibility of outsourcing key functions in the basic structure of the SC, such as provisioning, manufacturing, and distribution (block $\mathrm{P}$ ), by identifying the risks that may be associated with the outsourcing decision, i.e., loss of control of the process, underestimation of the cost of coordination, reduced supplier/customer contact, loss of internal capability, and growth in third-party power, leakage of sensitive information, loss of SC visibility, and negative reputational impact [39].

\subsubsection{Distribution Activity}

Regarding distribution activity, several options can be considered [40]:

- D1: Drop-shipping strategies. These can be identified as a manufacturer storage with direct shipping and/or in-transit merge. This option provides several benefits (high level of product availability with a lower level of inventory because of inventory centralisation at the manufacturer's premises and lower inventory needs can be obtained by postponing customisation), however, it also has some drawbacks (higher transport costs, high response times, poor customer service, and difficulty in handling returns), which can generate operational risks such as:

Transportation issues related to parcel carriers

Centralisation of inventories at the manufacturer can be a risk

- D2: Distributor storage strategies. These require a higher level of inventory (risks related to obsolescence, natural, or man-made events) and generate a higher transportation cost, especially in low population density areas, due to the use of last mile deliveries (although customer pick-up can also be considered). In regard to the operational risks associated with this option, we can highlight:

Inventory risks (obsolescence, natural, or man-made events)

Transportation issues due to last mile deliveries

- D3: Retail storage with customer pick-up. In this option, inventory is stored locally at retail stores, and customers either walk into the retail store or place an order and pick it up at the retail store. Some risks associated with this option are:

Product availability

Inventory risks. 


\subsubsection{Collection and Reprocessing Activities}

SCOP also defines options for end-of-use product collection and reprocessing activities related to the implementation of RLS.

According to Senthil et al. [41], in general, the current reverse logistics framework has not considered the risk management function, and so further research is required for the prioritisation of risk in reverse logistics in the product recovery network. Despite this statement, some elements can be described in this regard. Specifically, from a strategic point of view, considering return flows into the SC require a decision on the number, location, and capacity of the corresponding facilities (collection points, sorting and inspection facilities, recovery centres, etc.), designing the network (independent from the forward network vs. RLS), and the technological processes to implement (transportation systems, inspection, classification and recovery technologies, etc.), among others tasks. On the contrary, when deciding not to implement reverse logistics activities, one may consider the consequences at this stage of the SC network design. A complete analysis of the costs and benefits associated with the implementation of the reverse logistics system is provided in [42]. In any case, one of the main characteristics of the return flows is the uncertainty associated with the returned products, in terms of quantity, quality, and time $[43,44]$.

Regarding the collection activity, the following options can be considered:

- C1: OEM collection system. In this option, the collection is made directly by the manufacturer. The risks associated with this option are of the same type as those in the P1 option, i.e., Make of the Procurement and Production Activities:

\section{$\bigcirc \quad$ Operational disruptions due to natural or man-made events (HILF risks) \\ - Capacity issues \\ Technological obsolescence}

- C2: Distributor and retailer collection systems. With this option, the risks identified in the previous option are mitigated by being shared among the components of the distribution network. However, the risk of increased costs may appear due to the lack of economies of scale in the implementation and management of the collection system.

- C3: 3PL providers. In this case, the risks of outsourcing the activity must be evaluated, as mentioned in the P3 option, i.e., identify markets in the Procurement and Production activities.

Regarding the reprocessing activity, there are several types of risks to consider that can be derived from the uncertainties of the return flow. Regarding the uncertainty in the quantity of collected products, the risk of having, even temporarily, an insufficient or excess capacity to recover the product collected should be taken into consideration. As for the uncertainty in the quality of the product collected, there is a risk of not having adequate equipment to recover the product. Finally, the uncertainty of the time of collection can mean that the stores of the collected product pending recovery do not have adequate capacity. There is also the risk of not having enough to meet the demand for the recovered product.

In addition to the aforementioned risks, there are other specific SC risks for each recovery option, which are detailed below.

- R1: Recycling. This option consists of disassembling the collected product, obtaining one or more components that become part of other products (not necessarily of the same type), and depositing the rest in the environment. Exploiting economies of scale is indispensable in making recycling activities economically viable, so uncertainty concerning the supply volume is identified as a major risk [45].

- R2: Remanufacturing. This option consists of disassembling the product and replacing and rebuilding its components at least to the current specification [46]. Issues regarding remanufacturing capacity and quality uncertainties for the collected products can be identified as SC risks. 
- R3: Reuse. This option consists of cleaning and commissioning the collected product for reuse. In this option, quality uncertainty and risks involved with storage problems in terms of space, storage conditions, damaged products, and damage in storage (inventory risks) can be identified as potential SC risks [41].

\subsection{Stage 4: Microstructure}

The definition of SC microstructure is aimed at determining the facilities in which recipes will be developed, the volume of outcoming and incoming flows between facilities, and the respective transportation means [16]. As a general orientation, a recipe may be considered as the processes of transformation of inputs into outputs within the same facility. Concerning each facility, several decisions need to be made (location, ownership, capacity, transportation means, etc.) which can also be analysed from an SC risk point of view.

Once the elements of the microstructure have been determined, using the information obtained in stage 3, the risks associated with each element will be detailed and the way to assess the impact of each one on the performance of the SC will be determined. The methods of impact assessment can be qualitative or quantitative, although if they are qualitative, the way of incorporating that assessment into the mathematical models used to determine the optimal configuration of the SC will be defined.

Several approaches could be considered to introduce risk into SCND. According to Calleja et al. [47] most of the contributions use fuzzy numbers or the scenario approach. Plausible future scenarios must be developed to evaluate different possible designs, considering various types of uncertainties.

A type of uncertainty can be associated with the evolution of business-as-usual factors, which themselves can be associated with random variables. Several future scenarios can be considered based on the possible values of the random variables. Each of these scenarios has a probability of occurrence. As a result, one approach is to elaborate on and solve an average scenario. One alternative of this approach is to solve the resulting model for a subset of scenarios and evaluate the designs obtained. Another possibility is to incorporate a set of scenarios into stochastic mathematical programmes [28].

In addition to the above, risk disruptions are an important source of SC uncertainty, and should also be considered. The impact of such risk disruptions on companies could be considered in terms of monetary losses, both direct and indirect. Damages caused should be estimated in terms of design parameters such as capacity loss, supply loss, or demand surge. Consequently, adequate severity measures or SCND would have to be related to key design variables [11].

Several authors have proposed SCN performance measures for any plausible future business environment [48]. The measures employed to evaluate future SCN performances depend on the approach used to model uncertainty and on the attitude toward the risk of the decision-maker. There are two possible types of aversion to risk: performance measure variability and aversion to high-impact catastrophic events [14]. Some authors propose to incorporate maximum risk constraints in their model and use a multicriteria decision approach [49]. Another possibility is to consider risk measures such as mean-variance functions and conditional value at risk functions [14].

Under deep uncertainty, it is not possible to estimate a probability for plausible future scenarios. The scenarios associated with worst case events (very high impact-low frequency) can be elaborated through structured brainstorming sessions, expert interviews, and qualitative forecasting approaches such as the Delphi method [14].

\section{Illustrative Case Study}

In this section, we illustrate how SCOP-R works by applying the methodology to a real SC. The core entity in the SC is a family SME which has been producing high-quality flour for over 120 years. It is located in Catalonia and offers a proximity service to meet their customers' needs and generate greater value in their final products. Its distribution network encompasses the entire Iberian Peninsula, the Balearic Islands, the Canary Islands, and Southern France, with a fleet of trucks and cisterns ready to deliver the flour with maximum quality and speed. This case study was produced by 
using both primary and secondary information. Primary data was obtained from interviews with the CEO of the company who has great experience and is widely recognised in this industry, as well as a visit made to the company's facilities. Secondary information was obtained from corporate websites, research articles, annual reports, and other firm-specific documents.

\subsection{Stage 1: Object, Environment, and Objectives}

This section illustrates the application of the first stage of the SCOP-R methodology to the SC of a flour SME previously presented in this section.

\subsubsection{Definition of the Object, Environment, and SC Objectives}

Regarding our case study, flour is not the object, but high-quality flours for artisan bakers. Specifically, as it is declared by the company: "Our mission is to provide high-quality flours along with an excellent service, discovering the needs of our clients and accompanying them along the process of baking bread, in order to generate added value for their final products".

Therefore, the product of the SC is high quality flour. The main raw materials necessary for the elaboration of the product are wheat and other cereals (e.g., spelt and rye) of the highest quality and, if possible, within the proximity necessary to offer a sustainable product (zero kilometre, $100 \%$ local). In this case, the raw material of the local suppliers meets the quality and reliability requirements of the supply demanded by the company. The potential market to which the product is directed is that of artisan bakers mainly near Catalonia, although it also supplies flour to other areas of Spain. In any case, it is a locally scoped SC, that is, compact, intranational, and culturally homogeneous, unlike global SCs of a more international nature, with a greater geographic and culturally heterogeneous dispersion [13]. Its domestic and local characters make it less prone to certain risks and external threats more common in global CS, such as hazards (fire, floods, earthquake, or tsunamis), market forces (sudden demand change, competition, and price collapse), and economic or social forces (recession, labour instability, currency devaluation, political events, etc.) [13]. Global SC networks cause higher uncertainty, with unexpected and inevitable risks posing a higher likelihood of severe disruptions than domestic SCs $[1,8,50]$.

The environment in which the activity of the SC is carried out is that of the region close to Catalonia in which the stability of the local demand for artisanal bread and the seasonal demand for bread derived from tourism can be highlighted. It can be considered that the common flour market is in its maturity phase within the flour market for domestic consumption, in which the price of the product is a crucial factor for competitors. On the other hand, the market for quality flour for artisanal bread is in the not-so-mature market phase, in which it is possible to compete with factors other than price. The competitiveness of the product is maintained through innovation processes that facilitate the expansion of the product range, that is, the manufacture of different types of flours: organic, stone, rye, wholemeal, etc.

Because the characteristics of the raw material can vary depending on the weather and environmental conditions of the cereal crop, the characteristics of the flour can also vary depending on the supplier of the raw materials and even their characteristics, e.g., cereal could be different in different crops. The main objectives of the SC are to ensure both the quality of the product and the delivery service to its customers. An important aspect to consider to ensure product quality and customer satisfaction is that the characteristics of the flour supplied are those agreed with each customer.

\subsubsection{Scenario Identification}

The company considers a scenario of sustained growth in the demand for its product and does not consider substantial variations in competition. However, on the supply side of raw materials, the company foresees possible fluctuations in the availability and prices of raw materials, in particular, wheat. 


\subsubsection{Risk Identification}

Regarding the object of the SC, we can identify risks arising from the company's decision of the type of raw material used in its manufacturing process, which requires the selection of very specific suppliers, discarding the use of cheaper raw materials, albeit of lower quality, from Eastern Europe. Naturally, the impact of this risk related to the raw material will be evaluated at a later stage of this methodology, although we must warn of it now (e.g., in later stages, when considering whether, the SC is to be geographically more or less dispersed and global). Another of the most relevant risks linked to the object of an SC in the food sector is contamination and safety ([11]), whether the risk comes from involuntary causes (which could occur if both raw materials and the finished product had to travel long distances under conditions exposed to environmental or climatic risks of temperature and humidity) or is intentional (sabotage or negligence in handling, transport, and storage). The definition of the object of the SC implies taking these risks into account and making design decisions so that an acceptable level of risk is reached.

Regarding the environment, we can consider the risk of large economies, such as the Russian example, and block their wheat exports as wheat is a commodity whose price is referenced in the MATIF Index of the Paris Stock Exchange. This indicator can be further increased if the world's wheat supply decreases.

Other risks from the environment of great relevance in the food sector are weather conditions (e.g., droughts and frosts) and natural disasters (e.g., floods and fires) that can affect both the shortage and availability of raw materials such as the appearance of pests that also affect the finished product, specifically flour. The identification of these risks is of the utmost importance in these decisions, which must be taken at later stages of the SCOP-R methodology, related to the number and origin of the suppliers, as well as in the decisions on the distribution of the product. Table 2 summarises the risks identified at this stage.

Table 2. Risks associated with the definition of the object, environment, and objectives. The table shows the risk source for each criterion indicated in the columns, for each risk described in the rows.

\begin{tabular}{cccc}
\hline \multirow{2}{*}{ Risk Description } & \multicolumn{3}{c}{ Risk Sources Criteria } \\
\cline { 2 - 4 } & SC Vulnerability & Entity Level & Dimension \\
\hline Failure service level provided by raw material suppliers & External & Organisation & Product \\
Contamination and safety of raw material & External & Industry & Environment \\
Weather conditions and natural disasters & External & Environment & Environment \\
Price of the raw material & External & Environment & Product \\
\hline
\end{tabular}

\subsubsection{Risk Assessment}

Failures in the level of service of cereal suppliers, such as the lack of supply of cereals in the terms or at the agreed qualities, can have a significant long-term impact on the objectives of the SC, due to its effect on the trust of customers which could lead to a decrease in demand. The company considers that the risk is acceptable because it relies on the supply capacity of its suppliers to meet their needs in the expected scenario of sustained market growth. Therefore, it is considered a risk with consequences that are acceptable to the organisation.

The risk of contamination and safety of the raw material and the finished product may affect its quality. In this case, the company considers that the risk is mitigated through quality controls that exist at the different stages of the production process to verify the quality of the raw material, the semifinished product, and the finished product and through a thorough classification and mixing of the wheat. It is therefore an acceptable risk for the entity.

The variability of raw material prices may affect the operating result of the SC if the increase in costs (in this case, due to increase in cereal prices) cannot be transferred to the price of the finished product or cannot be compensated for with profit increase when cereal prices decrease. In this case, the company considers the risk of variability in the prices of raw materials acceptable because it makes 
a forecast of the mid-term prices when deciding the quantities of raw materials to purchase. In addition, being a market in which the quality of the product is valued, the price elasticity of demand is lower than that of flour; this allows the company to affect the increase in raw material costs in the sale price of the finished product. The identified risk is therefore classified as acceptable.

Climatic risks can block the transport of raw material from suppliers and also that of finished products to customers. We mainly refer to risks of rain and snow storms that could block road transport. The company considers that this is a very low frequency risk with a moderate impact, so it considers that its consequences are acceptable for the object and objectives of the SC defined.

\subsubsection{Redefinition of the Object, Environment, and Objectives}

In this case, it is considered that the object, environment, and objectives are compatible with the identified risks, so its modification is not required at this point in the design of the SC.

\subsection{Stage 2: Macrostructure}

This section illustrates the application of the second stage of the SCOP-R methodology through the case study of the flour SC.

\subsubsection{Definition of the Macrostructure}

Various activities of the P block of the SCOP methodology are present: raw material supply, flour manufacturing, and the distribution thereof. These activities are mainly carried out by the core entity of the SC (the flour manufacturing company). The company distributes the product directly to its customers in Catalonia and outsources the distribution to customers in other areas of Spain.

Regarding the U block (users, market, and customers), this is a SC with a local scope, that is, compact, intranational, and culturally homogeneous.

In this SC, other activities are carried out, namely, during the production process a by-product called bran is generated. If bran is detected in the finished product, it should be reintroduced into the production process in order to remove the bran by sifting the flour again, with all the guarantees of food safety and health. Moreover, the bran is a by-product that the flour company sells since it is used for animal feed. In addition, if contamination (presence of dirt, moisture, or insects) is detected during the procurement, production, and distribution phases, then the flour cannot be reintroduced into the production process since it is not suitable for human consumption, although it can be used in other industries, such as for animal feed. In this case, it would be identified in the SC macrostructure with an $\mathrm{S}$ block (secondary markets), from the P block. None of these activities involve reverse logistics activities of collection and recovery.

Therefore, in addition to the P and U blocks, the M-graph will include the Sblock (secondary market) corresponding to the flow of this by-product intended for animal feed.

\subsubsection{Scenario Identification}

Various scenarios can be considered that contemplate the possibility of performing various reverse logistics activities. In the previous section, we have seen that the scenario foreseen by the flour industry determines that the by-products and defective products can be used as raw material in the SC for animal feed (S block). However, we can also consider a scenario for the recovery of value of these products, e.g., regarding recycling flour in poor condition (low quality). In that case, an R block (remanufacturing/recycling) should be included in the definition of the macrostructure. Another scenario to study would be to accept customer returns, in which case, we should include a $\mathrm{C}$ block (collection) and a D block (disposal), if necessary, in the SC macrostructure. Figure 3 shows the M-graph of the three scenarios proposed. 


\subsubsection{Risks Identification}

It is possible to identify the risks associated with the activities of block $\mathrm{P}$, and the local/global aspect of the SC (block $U$ ). As previously mentioned, global versus local markets may be associated with "external" risks (HILF) such as hazards, political and social instability, cultural differences, sovereign default, etc., in addition to the risks associated with the (non)implementation of reverse logistics activities. Moreover, loss incurred in reprocessing the product or in selling the product in secondary markets, such as for animal food, should be considered.

There are several operational risks that must be considered to decide upon the best scenario of those raised in the previous section: security and health risks should be highlighted, e.g., risks of inventory contamination.

The supply risks of the primary and secondary markets for products recovered in reverse logistics processes must also be taken into account, such as deficient raw materials quality, market shortages, increase in material costs, and delivery delays. Table 3 illustrates the risks that must be considered when applying SCOP-R to this case study.

Table 3. Risks considered when applying stage 2 of Supply Chain Outline Process with Risk (SCOP-R) to the case study. The cells show the risk source for each criterion indicated in the columns, for each risk described in the row.

\begin{tabular}{cccc}
\hline \multirow{2}{*}{ Risk Description } & \multicolumn{3}{c}{ Risk Sources Criteria } \\
\cline { 2 - 4 } & SC Vulnerability & Entity Level & Dimension \\
\hline Deficient raw materials quality & External & Organisation & Product/processes \\
Inventory contamination & Internal & Organisation/environment & Infrastructure/environment \\
Product perishability and damage during distribution & Internal/external & Organisation/environment & Infrastructure/environment \\
Market shortages & External & Organisation & Product \\
Increase in material costs & External & Environment & Product \\
Delivery delays & Internal/external & Organisation & Infrastructure \\
\hline
\end{tabular}

\subsubsection{Risks Assessment}

In this phase of the SC's design (macrostructure), we cannot ascertain whether the frequency and impact of operational risks (inventory contamination and product perishability and damage during distribution) will be high or low. For an adequate estimate of these risks, more information is needed on the design of the mesostructure and microstructure of the SC. However, thanks to the experience of the flour company, we can estimate that these operational risks will be low-low (low frequency and low impact) and the probability of generating defective product, and therefore product susceptible to being recovered for refractory or recycling, is also low. Therefore, with adequate designs of the mesostructure and microstructure of the SC, it is estimated that product availability in the reverse logistics process will be low, and it is not necessary to include the corresponding reverse logistics blocks in the M-graph.

An increase in the demand for flour or cereal costs would be an incentive to increase the productivity of the production process. In this sense, these increases would favour decisions to improve the recovery processes of the bran which, in any case, should be contrasted with the associated costs. The flour company estimates that the impact of these risks does not compensate for the costs of improving the collection processes of the bran.

Regarding supply risks in secondary markets, the most relevant is the evolution of the demand and the costs of the raw material, in addition to the by-product that is intended to be recovered. A significant increase in the demand and/or costs of the animal feed market would be an incentive to recover the product in poor condition to be destined for the secondary market, and a stable evolution of these two indicators would discourage making the reverse logistics process profitable. The flour company estimates that the evolution of demand and raw material costs in the animal feed market would not be significant to encourage the improvement of the reverse logistics process. 


\subsection{Stage 3: Mesostructure}

This section illustrates the application of the third stage of the SCOP-R methodology to the SC of a flour company.

\subsubsection{Definition of the Mesostructure}

The flour production process consists of the cultivation, cleaning, wetting, and milling of the cereal and the sifting and bagging of the flour.

In most of its products, the flour company performs all the tasks in the process from the cleaning of the cereal (included). However, for a special type of flint-ground flour, the company has an agreement with a French company to act as a distributor. In the case of its own production, the company has a main supplier for each type of cereal and another secondary provider. The suppliers are mainly farmers and brokers. Although the harvest is in July, the company buys cereals throughout the year. Generally, it does not store wheat in large quantities. The company uses silos where it stores cereals to cover 1 month of production. The transportation of the raw material to the company is also outsourced. The company has two types of productions, mainly produced on demand. When they receive the customers' orders, they then pack the product and produce the highest turnover products against stock.

The company has a truck and a cistern to deliver the flour to some clients located in Barcelona and Girona, and subcontracts the direct transport of its products to the rest of the customers in the Catalonia area. For distribution to other areas, the company has outsourced three distributors with warehouses in Mallorca, Vilassar de Mar, and Castellón. In addition to managing it, the owner of the warehouse acts as a carrier and deliveryman. They also have distributors in other areas of Spain, e.g., in Madrid.

The company does not carry out any reverse logistics. However, when a high content of bran is detected, the product will be reprocessed in order to maintain the highest quality standards. If a contaminated lot is detected, the product will be reallocated as animal feed, as well as the bran obtained during the production process.

\subsubsection{Scenario Identification}

Regarding the procurement and production activities, various scenarios can be raised in which different options are proposed. In particular, the option of buying the final product from external suppliers is contemplated, that is, subcontracting the flour production process in products other than ground flour to flint stone and the option of growing cereal instead of buying grain. The option of increasing or decreasing the number of suppliers for each type of raw material and the possibility of increasing the amount of raw materials stored in company warehouses is also evaluated.

The option of doing all the distribution activities with its own distribution means is contemplated by the company.

End-of-use products are not liable to be collected as their economic value is scarce and the impact on the environment is minimal. Therefore, it is not necessary to deploy a reverse logistics system to collect and recover end-of-use products.

\subsubsection{Risks Identification}

In the current scenario, in which the company carries out most of the production process, the operational risks related to the failure of the production equipment and accidents due to lack of security must be assessed. Another risk is that of staff turnover; the lack of qualified personnel is one of the problems noted by the company, as is the need to train its staff. In the scenario of buying flour from supplier companies, the main risks are, on the one hand, that suppliers are not able to supply flour with the quality and reliability required by the company and, on the other, if they were able to do so, there is a risk that the supplier will try to cannibalise the company's demand by directly supplying the company's customers. As for the option of growing cereals, there is a risk of not having enough knowledge to produce cereals of the required quality and variety, in addition to the fact that 
the costs could increase. Regarding the number of suppliers of raw material (cereal grain), with a single supplier, there is a risk of failure in the level of service of the supplier (e.g., failure in the quality of the product or in terms of supply due to strikes or bad weather), whereas if there is more than one supplier, there is a risk of having higher supply costs. In relation to the storage options of the raw material, if it is the responsibility of the supplier, the cost that it has compared to the cost of its own storage has to be evaluated, considering the risk of deterioration of the stored raw material.

Supply risks, operational risks, and additional risks due to outsourcing transport and distribution should be identified. Due to the distribution of the product to other Spanish regions being externalised, one of the most relevant risks to consider by the flour company is the product's perishability and risk of damage during the distribution process caused, e.g., by inappropriate conditions of temperature and humidity in the warehouses and in transportation. Another risk to consider would be deficient product delivery to customers that could impact on their satisfaction and loyalty to the flour company. Table 4 shows the risks to consider when applying SCOP-R to this case study.

Table 4. Risks considered during stage 3 of SCOP-R applied to the case study. The cells show the risk source for each criterion indicated in the columns, for each risk described in the row.

\begin{tabular}{cccc}
\hline \multirow{2}{*}{ Risk Description } & & Risk Sources Criteria & \\
\cline { 2 - 4 } & SC Vulnerability & Entity Level & Dimension \\
\hline Production equipment failures & Internal & Organisation & Infrastructure \\
Production staff lack of skills & Internal & Organisation & Human resources \\
Noncompliance of service level agreements by providers & External & Organisation & Product \\
Market competitor's growth & External & Industry & Environment \\
Lack of knowledge of production processes & Internal & Organisation & Processes \\
Product deterioration & Internal/external & Organisation/environment & Infrastructure/environment \\
Delivery delays & Internal/external & Organisation & Infrastructure \\
\hline
\end{tabular}

\subsubsection{Risks Assessment}

The flour company considers that the operational risks of the current scenario are of high impact and medium frequency. To mitigate the effect of these risks, the company has heavily invested in preventive maintenance of the productive equipment to have it in optimal conditions. Moreover, the company has reached agreements with machinery suppliers to minimise the impact when failures occur in equipment components (the bagger and the palletiser, most notably).

The company considers that the risks of outsourcing manufacturing activities is not acceptable due to the difficulty of finding suppliers that can satisfy their quality requirements. It also considers the risks of growing the cereal to not be acceptable due to the lack of experience in this type of activity and due to the high start-up cost.

It is considered that grain cereal suppliers cannot always meet the deadlines and product quality required by the company. The frequency of noncompliance, although low, is not acceptable because of the high impact it can have on production and therefore, on the satisfaction of the customers of the flour mill (normally customers acquire product to consume within a few days, so if the flour fails in the supply, it could leave customers without the raw material needed for their production process).

Regarding the risks of increasing the amount of raw material stored in the facilities themselves or leaving it in those of the supplier, it is of the opinion that, with the current level of production, the costs of maintaining a new warehouse in the appropriate conditions so that the cereal grains do not spoil or become contaminated are higher than the extra cost that is paid when the provider stores it in their own facilities.

The company has assessed the risks of having its own means of transport for product distribution. It considers that, with the current level of operations, the impact of the risks is much greater than that of the risks associated with outsourcing. 


\subsection{Stage 4: Microstructure}

At this stage, decisions are made with the help of several mathematical models. In the literature, several models that incorporate risk are available, which could be useful (we invite the reader to consult literature reviews on mathematical models for SCND, e.g., [51-53] for food and sustainable agro-food SCND, respectively).

\section{Conclusions and Further Research}

Throughout this work, the importance of considering the different risks that affect the SC during its design process has been highlighted. To this end, a proposal has been made to classify the risks that affect the SC, and thus facilitate the process of identifying them, which is considered to be a key element in the typical process of SCRM [54]. Based on a methodology already in contrast to the design of the SC [16], a procedure for the identification and assessment of the risks in the SC has been developed to make the design decisions accordingly. The methodology, which we call SCOP-R, proposes the incorporation of the risk factor (SC risk) in each of the stages of the SC design process. An application of such a methodology is illustrated through a case study on a SC of the agri-food industry in Spain. As a result, we observe that the main risks identified when applying SCOP-R to this case are coherent to those identified previously in other works related with agri-food SC [18,50,51]. However, unlike them, where different risk measures are proposed, SCOP-R, through a risk identification and assessment procedure, helps make strategic design decisions that determine a specific configuration of the SC.

There are several conclusions that arise from this research study. First, the relevance of considering the risk factor in the early stages of the design of the SC to anticipate the effects and consequences of such risks, both in terms of their impact and frequency was studied. From the initial design phase of the SC, it is possible to identify the risks associated with the design decisions related to the object, environment, and objectives of the SC. In fact, this systematic approach for considering the risks in the design of the SC allows us to identify such risks and, where appropriate, modify the design decisions of the structure of the SC. In line with previous work, the early identification of risks is a key aspect of the proposed methodology, so in each of the stages of the SCOP-R, the first task will be to identify potential SC risks. According to the proposed methodology, we have highlighted the importance of considering all of the priori relevant design options in each stage and their risks in order to select the best alternative for a resilient SC. We suggest that several design decisions should be made, including risk considerations before the use of a mathematical model, to discover the optimal design in the microstructure stage of the SCND.

Second, risk identification is not a closed issue in the SCRM literature, and there remains debate about typologies and risk classifications, which allow different typologies for different SCs to be identified based on, e.g., the sector they belong to, their scope (local or global), competitive priorities, etc. Therefore, more research should be conducted in different contexts and industrial sectors, because some risks relevant to SCs in the food industry (such as product contamination and safety) could differ from other sectors. In this particular case of a flour SC, this methodology has allowed us to identify SC risks such as raw material quality, inventory contamination, perishability, distribution failures, and delays, which could prevent the achievement of SC objectives. In addition, the consequences of these risks, both in terms of their impact and frequency, may vary between different SCs, depending on their own characteristics and circumstances. Hence, we must continue investigating the processes of risk identification and the evaluation of their possible impacts.

Finally, as Calleja et al. [47] suggest that more effort should be made to more comprehensively develop a methodology based on a succession of stages to serve as an effective guide to SCND practitioners.

Author Contributions: Conceptualisation, E.B., C.M.-C. and S.R.; formal analysis, E.B., C.M.-C. and S.R.; investigation, E.B., C.M.-C. and S.R.; methodology, E.B., C.M.-C. and S.R.; writing-original draft, E.B., C.M.-C. and S.R.; writing-review and editing, E.B., C.M.-C. and S.R. All authors have read and agreed to the published version of the manuscript. 
Funding: This research is supported by the "Conceptos, Instrumentos, Modelos y Algoritmos para el Diseño de la Supply Chain (CIMADISC)" project, funded by Ministerio de Economía y Competitividad and Fondo Europeo de Desarrollo Regional (FEDER) (Grant Number: DPI2015-67740-P).

Conflicts of Interest: The authors declare no conflicts of interest.

\section{References}

1. Blackhurst, J.; Craighead, C.W.; Elkins, D.; Handfield, R.B. An empirically derived agenda of critical research issues for managing supply-chain disruptions. Int. J. Prod. Res. 2005, 43, 4067-4081. [CrossRef]

2. Rao, S.; Goldsby, T.J. Supply chain risks: A review and typology. Int. J. Logist. Manag. 2009, 20, 97-123. [CrossRef]

3. Haberman, M.; Blackhurst, J.; Metcalf, A.Y. Keep your friends close? Supply chain design and disruption risk. Decis. Sci. 2015, 46, 491-526. [CrossRef]

4. Agigi, N.; Niemann, W.; Kotzé, T. Supply chain design approaches for supply chain resilience: A qualitative study of South African fast-moving consumer goods grocery manufacturers. J. Transp. Supply Chain Manag. 2016, 10, 1-15. [CrossRef]

5. Hudnurkar, M.; Deshpande, S.; Rathod, U.; Jakhar, S.K. Supply chain risk classification schemes: A literature review. Oper. Supply Chain Manag. 2017, 10, 182-199. [CrossRef]

6. Zhu, Y.; Xie, C.; Sun, B.; Wang, G.-J.; Yan, X.-G. Predicting China's SME Credit Risk in Supply Chain Financing by Logistic Regression, Artificial Neural Network and Hybrid Models. Sustainability 2016, 8, 433. [CrossRef]

7. Dolgui, A.; Ivanov, D.; Sokolov, B. Ripple effect in the supply chain: An analysis and recent literature. Int. J. Prod. Res. 2018, 56, 414-430. [CrossRef]

8. Craighead, C.W.; Blackhurst, J.; Rungtusanatham, M.J.; Handfield, R.B. The severity of supply chain disruptions: Design characteristics and mitigation capabilities. Decis. Sci. 2007, 38, 131-156. [CrossRef]

9. Ellis, S.C.; Henry, R.M.; Shockley, J. Buyer perceptions of supply disruption risk: A behavioral view and empirical assessment. J. Oper. Manag. 2010, 28, 34-46. [CrossRef]

10. Rangel, D.A.; de Oliveira, T.K.; Alexandre, M.S. Supply Chain Risk Classification: Discussion and Proposal. Int. J. Prod. Res. 2015, 53, 6868-6887. [CrossRef]

11. Speier, C.; Whipple, J.M.; Closs, D.J.; Voss, M.D. Global supply chain design considerations: Mitigating product safety and security risks. J. Oper. Manag. 2011, 29, 721-736. [CrossRef]

12. Ivanov, D.; Dolgui, A.; Sokolov, B.; Ivanova, M. Literature review on disruption recovery in the supply chain. Int. J. Prod. Res. 2017, 55, 6158-6174. [CrossRef]

13. Sáenz, M.J.; Revilla, E.; Acero, B. Aligning supply chain design for boosting resilience. Bus. Horiz. 2018, 61, 443-452. [CrossRef]

14. Klibi, W.; Martel, A.; Guitouni, A. The design of robust value-creating supply chain networks: A critical review. Eur. J. Oper. Res. 2010, 203, 283-293. [CrossRef]

15. Farahani, R.Z.; Rezapour, S.; Drezner, T.; Fallah, S. Competitive supply chain network design: An overview of classifications, models, solution techniques and applications. Omega Int. J. Manag. Sci. 2014, 45, 92-118. [CrossRef]

16. Corominas, A.; Mateo, M.; Ribas, I.; Rubio, S. Methodological elements of supply chain design. Int. J. Prod. Res. 2015, 53, 5017-5030. [CrossRef]

17. Tang, C.S. Robust Strategies for Mitigating Supply Chain Disruptions. Int. J. Logist. Res. Appl. 2006, 9, 33-45. [CrossRef]

18. Vlajic, J.V.; van der Vorst, J.G.A.J.; Haijema, R. A Framework for Designing Robust Food Supply Chains. Int. J. Prod. Econ. 2012, 137, 176-189. [CrossRef]

19. Wieland, A. Selecting the right supply chain based on risks. J. Manuf. Technol. Manag. 2013, 24, 652-668. [CrossRef]

20. Fan, Y.; Stevenson, M. A review of supply chain risk management. Int. J. Phys. Distrib. Logist. Manag. 2018, 48, 205-230. [CrossRef]

21. Oke, A.; Gopalakrishnan, M. Managing disruptions in supply chains: A case study of a retail supply chain. Int. J. Prod. Econ. 2009, 118, 168-174. [CrossRef]

22. Heckmann, I.; Comes, T.; Nickel, S. A critical review on supply chain risk: Definition, measure and modeling. Omega Int. J. Manag. Sci. 2015, 52, 119-132. [CrossRef]

23. Díaz-Curbelo, A.; Gento, Á.M.; Redondo, A.; Aqlan, F. A Fuzzy-Based Holistic Approach for Supply Chain Risk Assessment and Aggregation Considering Risk Interdependencies. Appl. Sci. 2019, 9, 5329. [CrossRef] 
24. Klibi, W.M.; Martel, A. Scenario-based supply chain network risk modeling. Eur. J. Oper. Res. 2012, 223, 644-658. [CrossRef]

25. Viswanadham, N.; Gaonkar, R.S. Risk Management in global supply chain networks. In Supply Chain Analysis. A Handbook on the Interaction of Information, System and Optimization; Tang, C.S., Teo, C., Wei, K., Eds.; Springer: New York, NY, USA, 2008; pp. 201-221.

26. Akkermans, H.A.; Van Wassenhove, L.N. Supply chain tsunamis: Research on low-probability, high-impact disruptions. J. Supply Chain Manag. 2018, 54, 64-76. [CrossRef]

27. Sheffi, Y.; Rice, J.B., Jr. A supply chain view of the resilient enterprise. MIT Sloan Manag. Rev. 2005, 47, 41-48.

28. Klibi, W.; Martel, A. The design of robust value-creating supply chain networks. OR Spectr. 2013, 35, 867-903. [CrossRef]

29. Torabi, S.A.; Namdar, J.; Hatefi, S.M.; Jolai, F. An enhanced possibilist programming approach for reliable closed-loop supply chain network design. Int. J. Prod. Res. 2015, 54, 1358-1387. [CrossRef]

30. Akkermans, H.A.; Van Wassenhove, L.N. Searching for the grey swans: The next 50 years of production research. Int. J. Prod. Res. 2013, 51, 6746-6755. [CrossRef]

31. Shi, D. A review of enterprise supply chain risk management. J. Syst. Sci. Syst. Eng. 2004, 13, 219-244. [CrossRef]

32. Melnyk, S.A.; Narasimhan, R.; De Campos, A. Supply chain design: Issues, challenges, frameworks and solutions. Int. J. Prod. Res. 2014, 52, 1887-1896. [CrossRef]

33. Park, Y.W.; Hong, P.; Roh, J.J. Supply chain lessons from the catastrophic natural disaster in Japan. Bus. Horiz. 2013, 56, 56-75. [CrossRef]

34. Thun, J.H.; Hoenig, D. An empirical analysis of supply chain risk management in the German automotive industry. Int. J. Prod. Econ. 2011, 131, 242-249. [CrossRef]

35. Hopkins, M.S. Your next supply chain. MIT Sloan Manag. Rev. 2010, 51, 17-24.

36. Prakash, S.; Soni, G.; Rathore, A.P.S. Embedding risk in closed-loop supply chain network design: Case of a hospital furniture manufacturer. J. Model. Manag. 2017, 12, 551-574. [CrossRef]

37. Flapper, S.D.P.; Van Nunnen, J.A.E.E.; Van Wassenhove, L.N. Managing Closed-Loop Supply Chains; Springer: Berlin, Germany, 2005.

38. Rubio, S.; Jiménez-Parra, B. Reverse logistics: Concept, evolution and marketing challenges. In Optimization and Decision Support Systems for Supply Chains; Miranda, J.L., Barbosa-Póvoa, A.P., Corominas, A., Eds.; Springer: Berlin, Germany, 2017.

39. Chopra, S.; Meindl, P. Supply Chain Management; Strategy, Planning, and Operation; Pearson: London, UK, 2013.

40. Ribas, I.; Lusa, A.; Corominas, A. A framework for designing a supply chain distribution network. Int. J. Prod. Res. 2010, 57, 2104-2116. [CrossRef]

41. Senthil, S.; Murugananthan, K.; Ramesh, A. Analysis and priorisation of risks in a reverse logistics network using hybrid multi-criteria decision making models. J. Clean. Prod. 2018, 179, 716-730. [CrossRef]

42. Dowlatshahi, S. A cost-benefit analysis for the design and implementation of reverse logistics systems: Case studies approac. Int. J. Prod. Res. 2010, 48, 1361-1380. [CrossRef]

43. Thierry, M.; Salomon, M.; Van Nunen, J.; Van Wassenhove, L. Strategic issues in product recovery management. Calif. Manag. Rev. 1995, 37, 114-136. [CrossRef]

44. Dekker, R.; Fleischmann, M.; Inderfurth, K.; Van Wassenhove, L.N. Reverse Logistics. Quantitative Models for Closed-Loop Supply Chains; Springer: Berlin, Germany, 2004.

45. Fleischmann, M. Quantitative Models for Reverse Logistics; Lecture Notes in Economics and Mathematical Systems 501; Springer: Berlin/Heidelberg, Germany, 2001.

46. Ilgin, M.A.; Gupta, S.M. Remanufacturing Model and Analysis; CRC Press: Boca Raton, FL, USA, 2012.

47. Calleja, G.; Corominas, A.; Martínez-Costa, C.; de la Torre, R. Methodological approaches to supply chain design. Int. J. Prod. Res. 2018, 56, 4467-4489. [CrossRef]

48. Sheffi, Y. The Resilient Enterprise: Overcoming Vulnerability for Competitive Advantage; MIT Press: Cambridge, MA, USA, 2005.

49. Eppen, G.D.; Martin, R.K.; Schrage, L. A scenario approach to capacity planning. Oper. Res. 1989, 37, 517-527. [CrossRef]

50. Bakshi, N.; Kleindorfer, P. Co-opetition and investment for supply chain resilience. Prod. Oper. Manag. 2009, 18, 583-603. [CrossRef]

51. Govindan, K.; Fattahi, M.; Keyvanshokooh, E. Supply Chain network design under uncertainty. Eur. J. Oper. Res. 2017, 263, 108-141. [CrossRef] 
52. Akhmad, S.; Miswanto; Suprajitno, H. Interval model for food supply chain network at the multi stage distribution systems. Int. J. GEOMATE 2019, 16, 125-130. [CrossRef]

53. Allaoui, H.; Guo, Y.; Choudhary, A.; Bloemhof, J. Sustainable agro-food supply chain design using two-stage hybrid multi-objective decision-making approach. Comput. Oper. Res. 2018, 89, 369-384. [CrossRef]

54. Kern, D.; Moser, R.; Hartman, E.; Moder, M. Supply risk management: Model development and empirical analysis. Int. J. Phys. Distrib. Logist. Manag. 2012, 42, 60-82. [CrossRef]

(C) 2020 by the authors. Licensee MDPI, Basel, Switzerland. This article is an open access article distributed under the terms and conditions of the Creative Commons Attribution (CC BY) license (http://creativecommons.org/licenses/by/4.0/). 